\title{
ROLE OF ORGANIC CONTENT FOR THE GEOTECHNICAL BEHAVIOUR OF CLAYS
}

\author{
ROLAND PUSCH \\ Department of Civil, Environmental and Natural Resources Engineering, \\ Luleå University of Technology, Sweden
}

\begin{abstract}
Organic matter in clays often controls their geotechnical behaviour because of its influence on the strength and strain properties in bulk. It is integrated in the clay particle matrix and serves as a weak ductile component to an extent that depends on the degree of decomposition, which is a function of the moisture conditions, temperature and microfauna. Nematodes and arthropods, bacteria and fungi feed on it and make the soil porous, allowing infiltration of air and water. In the final stage of decomposition, the rest product is humus. The function of organic constituents in clay depends on the atomic and molecular bonds within them and between them and the clay minerals. Under moderate deviatoric bulk stress conditions, strain occurs in the molecular scale involving slip when energy barriers, determined by the bond strength, are overcome. Shearing makes the slips accumulate and causes successive changes of the energy bond spectrum, implying that low-energy barriers are used while high-energy barriers become dominant. For low and moderate safety factors, this leads to a blueshift of the spectrum and to stiffening and brittleness. The mineral phase has a certain barrier spectrum, while the organics have their own, implying rapid overcoming of the lower-energy barriers. This results in large shear strain and higher strain rate and lower shear strength and 'quickness'. Organic clay undergoes creep strain that is similar to that of smectite clay and controls long-term settlement of buildings and the stability of natural and excavated slopes.
\end{abstract}

Keywords: clay, creep, energy barrier, humus, illite, microstructure, sensitivity, shear stress/strain, smectite

\section{SCOPE}

The aim of this study is to find if the rheological behaviour of fine-grained clastic soil materials exposed to moderate bulk shear stresses can be described by using thermodynamically based stress/strain models, implying the shear resistance to be generated by transfer from lowenergy to high-energy atomic or molecular barriers associated with slip on the atomic level. This has been demonstrated for inorganic clay [1] and is proposed here also for organic clay.

\section{ORGANIC CONSTITUENTS IN SEDIMENTARY CLAY}

\subsection{Nature formation}

Organic matter in soils is represented by fruits, leaves, roots and microscopic material such as fragments of plants and animals, pollen, microorganisms, organic molecules and compounds [2]. As the residues breakdown, stable molecules remain like aromatic carbon rings, oxygen and hydrogen in the form of humin, lignin and lignin complexes, which are collectively called humus. It is a weakly acid colloid with considerable cation- and anion-exchange capacities, representing the end product of successive degradation of humic and fulvic acids, which begin as raw organic matter and attacks silicate minerals resulting in free silica and silicious compounds such as $\mathrm{H} 4 \mathrm{SiO} 4$ serving as weak cementing agents.

Lignin is resistant to breakdown and accumulates within the soil. It also reacts with amino acids, which further increases its resistance to decomposition, including enzymatic 
decomposition by microbes. Fats and waxes from plant matter have some resistance to decomposition and persist in soils for some time. Proteins normally decompose readily, but when bound to clay particles, they become more resistant to decomposition. Clay particles also absorb the enzymes exuded by microbes, which would normally breakdown proteins.

Organic molecules and compounds in clayey soils are mainly products of the action of microorganisms [3-5]. Owing to the special and surface properties, microorganisms are the most important organic constituents in clay. The origin of microorganisms in glacial clays dates back to the time when they were formed ten to 20,000 years ago. The content of microorganisms in the present oceans indicates the amount and types of species that were deposited together with clay particles. The microfauna in present oceans consists of unicellular protozoa, nematodes, bacteria and crustacea, while the microflora contains fungi and algae. In cold oceans like those in which glacial clays were formed, the dominant members of the microflora are silicic algae [4]. In warmer sea, blue-green algae are frequent, and they were probably dominant also during parts of the period, when Quaternary clays were deposited. Fairly large numbers of bacteria and fungi are found in present oceans and they were frequent also in glacial time.

The amount of microorganisms in the oceans is illustrated by the number of bacteria, which presently ranges between E3 and 3E5 per millilitre at depths between 10 and $50 \mathrm{~m}$ below the seal level [4], while the number of fungi is considerably smaller. In the Arctic Sea, where glacial clay was deposited, the number of bacteria may not have been very different, while fungi - alive, dormant or dead - can be higher than today because of the presence of fragments of pre-glacial vegetation brought to the sea by rain and meltwater.

\subsection{Practical role of organic content in natural clay}

As concerns the organic matter on the geotechnical performance of sedimentary clay, some is of limited importance while others control the physical behaviour [6]. We will deal here with clays with an organic content of about five weight per cent as determined by incineration are analysed. Some of the organic material can be in fibre form and more or less degraded microorganisms, as well as strongly degraded humus [4]. In general, the stress/strain behaviour is similar to that of amorphous bodies within which there are considerable variations in activation for flow. The ways in which organic components are coupled to clay minerals allow us to apply rate process theory for describing the deformation both on the microstructural scale and on bulk scale as will be shown here.

\subsection{Microstructure of organic clays}

The general microstructural constitution of freshwater and marine clays is illustrated by the schematic picture and micrographs in Fig. 1.

Considering organic constituents or precipitations generated by organic activity, one can take amorphous humus constituents and bacteria into consideration in the first place. The volume of a single organic element, taken as E-15 $\mathrm{m}^{3}$, would make up $0.01-100 \%$ of the pore volume of many glacial clays with a density of $1,500-2,000 \mathrm{~kg} / \mathrm{m}^{3}$ at water saturation. They have a median void size of $0.1-50 \mu \mathrm{m}$, which illustrates the great importance of organic elements for the physical properties of clays in bulk (cf. Fig. 2).

The 'rubber' model in Fig. 3, consisting of a network of deformable fibres or chains of organic molecules that bind together stiffer units, is a prototype for organic clay. It can be assumed to have the type of microstructure shown to the right in the figure. 


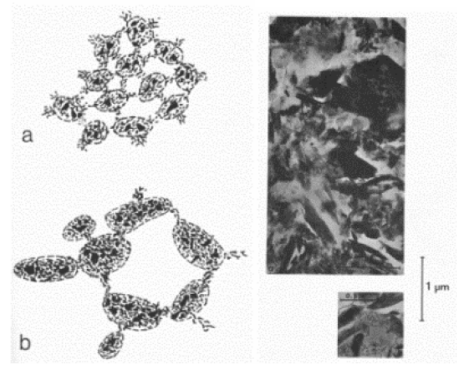

Figure 1: Illitic clay microstructure. Left: Schematic drawing of equally dense (a) freshwater clay (b) marine clay. Right: Electron micrograph of post-glacial freshwater clay [4].
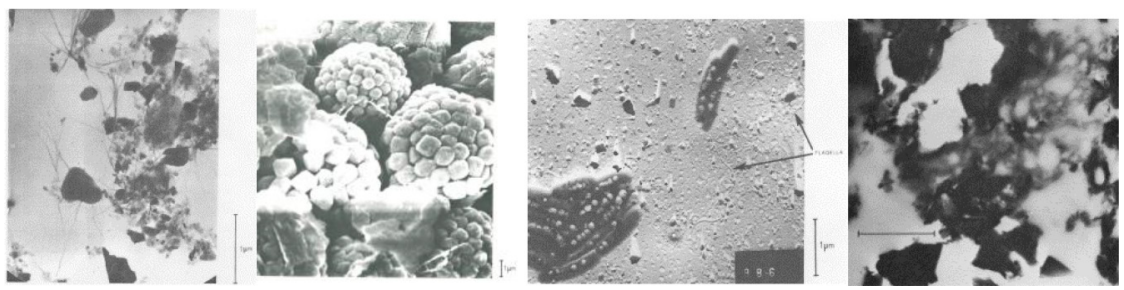

Figure 2: From left: (1) TEM micrograph of fibrous organic tissues binding clay particles together. (2) Pyrite aggregates ('nodules') generated by organic activity and almost totally occupying the pore space of post-glacial marine clay (SEM, scanning electron micrograph). (3) TEM micrograph of bacteria in post-glacial soft clay at $2 \mathrm{~m}$ depth. (4) TEM micrograph of organic clay rich in iron sulphide with network of organic residue [7].
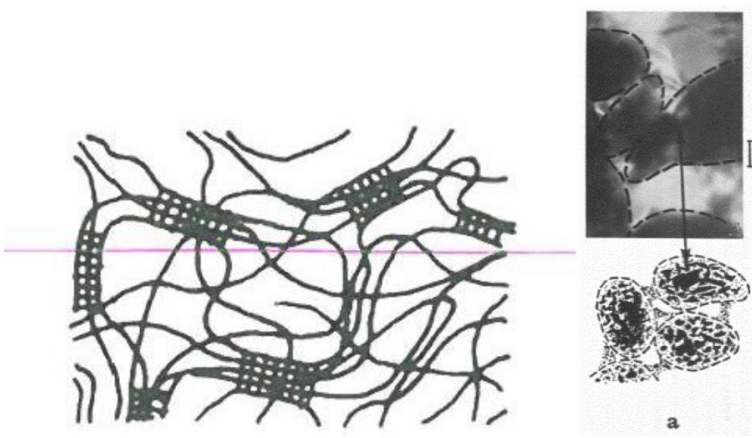

Figure 3: Fibrous microstructure. Left: Fringed micelle structure of an unoriented crystalline polymer with dense elements (After Morton and Hearle). Right: Dense clay particle aggregates glued together by soft gel elements of clay or organic matter [8].

\subsection{Interparticle bond strength in organic illitic and smectitic clays}

Interparticle bonds between clay minerals are primarily of primary valence type, hydrogen bonds or shared bonds between cations held closely to adjacent particles [9]. They represent different energies and make up an energy spectrum ranging from very low to energy levels like London/van der Waals bonds and hydrogen bonds, to strong primary valence bonds. 

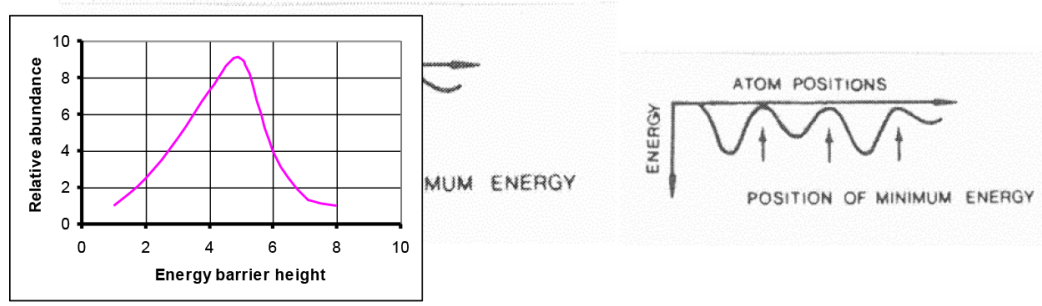

Figure 4: Left: Energy bond (barrier) spectrum ranging over 1-8 eV. Right: Energy bond variation along a clay particle surface [10].
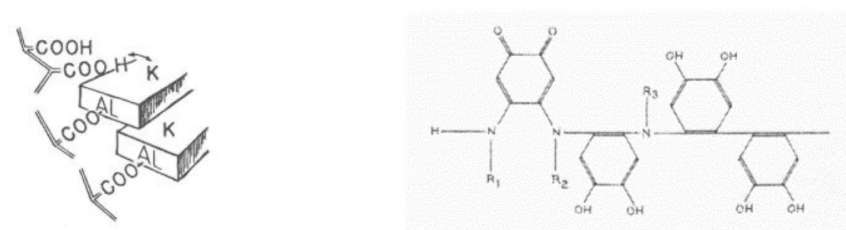

Figure 5: Example of chemical bonds. Left: Carboxyls coupled to clay mineral edges by hydrogen bonds exchangeable by potassium. Right: Proposed arrangement of humic acid polymers containing phenols and amino acids [4].

Clays with an appreciable organic content are hence characterized by a bond energy spectrum that can look like the one in Fig. 4. Bonds between clay mineral particles and organic tissues can be of the types shown in Fig. 5. Functional groups, like carboxyls $(\mathrm{COOH})$, phenols and alcohol $(\mathrm{OH})$, methoxyl $\left(\mathrm{OCH}_{3}\right)$, carbonyl $(\mathrm{C}-\mathrm{O})$ and quinone $(\mathrm{C}=\mathrm{O})$, play a significant role by exchanging the hydrogen ion against various bases, the molecular structure being formed by aromatic (hydrophobic) and aliphatic (hydrophilic) rings and side chains. Ammonia $\left(\mathrm{NH}_{3}\right)$ is found to establish frequent bonds to clay mineral particles as well.

\subsection{Shear strain and strength of organic clay}

A theoretical stress/strain model worked out for inorganic clay was proposed by Pusch and Feltham [1] and will be used also for organic clays in this article due to its unique potential to encompass the stochastic nature and process of slip, failure and reformation of interparticle bonds in very fine-grained clayey soils. The microstructural model needed for developing a theoretical model for the performance of a generalized stress/strain model, applicable to shearing, compression and consolidation, is taken here to be of the types shown in Fig. 3.

\section{EXPERIMENTAL}

\subsection{Scope of tests}

The overall aim of the study was to find evidence of the role of organic constituents in natural clays respecting fundamental stress/strain properties in bulk. This required selection and characterization of suitable clay materials and comparison of the geotechnical properties of samples with their natural content of organic material and samples with such material removed. 
Since comparison requires that the clay samples have the same density and microstructural constitution, each of four raw materials was processed to prepare 'analogous' versions with similar density and water content for determining their characteristic bulk properties. All the raw material clays were of marine origin with different geotechnical properties with respect to water content, density and shear strength and mineralogical constitution. It was expected that the most obvious measure of the role of the organics would be a change in shear strength after percolation with distilled water as exhibited by a change in sensitivity $\left(S_{\mathrm{t}}\right)$, i.e. the ratio of the undrained shear strength of undisturbed and remoulded clay.

\subsection{Background of test programme}

It has long been discussed whether organic matter can play a role in the formation of 'quick' illitic clay of marine origin. The traditional explanation of their high sensitivity is that the particle network, formed in salt water, remains stable in undisturbed form in nature if the clay has later been percolated with freshwater, while dispersion occurs by remoulding. Some researchers have claimed that 'quickness' can be caused by infiltration of dispersive organic agents, cf. [11]), but it may also be ascribed to the action of soluble natural organic components. Thus, some organic matter, like humus, is known to form cementing compounds, especially in the presence of polyvalent cations, by which cementing gel complexes with humic acid are formed [2]. Subsequent percolation with freshwater would dissolve them and weaken the clay microstructure, hence increasing the sensitivity. The same effect has been observed for other organic matter, such as cellulose polyacrylonitrile, used in erstwhile USSR for improving drilling muds [6]. Such organics, serving as reinforcement in natural clay, can be dissolved and lost by percolation with freshwater or low-salt groundwater. Permeation of natural clay may hence raise the sensitivity ratio $S_{\mathrm{t}}$ in two ways: infiltration of organics with dispersive properties or removal of organics with cementing properties. For investigating this matter, a series of experiments have been made with leached and unleached marine clays.

\subsection{Laboratory test series}

Undisturbed samples were taken from Quaternary natural and normally to highly sensitive marine clays in the Göta River valley. The geotechnical properties of the raw materials are summarized in Table 1. Samples extracted from them were used for preparing analogues by drying, grinding, and sedimentation in ocean water and consolidation for subsequent percolation with distilled water of one sample of each material and determination of the sensitivity. Tests of commercial illite ('Grundite') from which organic substances had been removed by prolonged repeated treatment with diluted hydrogen peroxide, had shown that such treatment did not affect the clay minerals as concluded from XRD analyses [4].

\subsection{Preparation of analogous clays for testing}

Raw clay samples, dried at $60^{\circ} \mathrm{C}$, were crushed and milled for artificial preparation of analogous samples, which included preparation of a solution of $35 \mathrm{~g} / \mathrm{l}$ ocean water passed through $0.45-\mu \mathrm{m}$ Millipore filters, for mixing with the clay powder in question to a water content of about $1,000 \%$. The suspensions were consolidated in cells to obtain the same water content, slightly lower than $w_{\mathrm{L}}$ of the raw material, for each pair of samples, i.e. one with the organic content preserved by leaving the sample without percolation and the other for several cycles of percolation with distilled water. 





Percolation of one of each of the pair of the analogous samples was made by applying a hydraulic gradient of $50 \mathrm{~m}$ water head per metre flow length of distilled water, letting the flow proceed until the discharged water had a salt content lower than $5 \mathrm{~g}$ per litre. Chemical analysis of alcohol-extracted samples of Quaternary marine, illitic clays in separate series showed that the yellowish to brownish leachates (Fig. 6) had, as major component, the amino acid $\mathrm{NH}_{3}(0.118-0.361 \mu \mathrm{M} / \mathrm{ml})$.

\subsection{Results from sensitivity tests}

Figure 7 compares the sensitivity of the analogous clays prepared from the raw materials termed I, II, III and IV and described in Table 1.

The conclusion one can draw is that leaching with distilled water raised the sensitivity of all the clays (I-IV). Except for the one from Ellesbo (IV), for which $S_{\mathrm{t}}$ increased from about 11 to about $130, S_{\text {t }}$ rose from $8-16$ to about 50 . For the leached organic clays, the sensitivity increased so much that only a minimum value, 105-210, could be determined. The study indicates that leaching of natural marine clay is necessary for transforming them to 'highsensitivity' clay but that a certain minimum organic content of about $2 \%$ is required to cause significant 'quickness'. The reason for this may be twofold: first, leaching may convert humic compounds to dispersive agents and secondly that such matter or other forms of organic

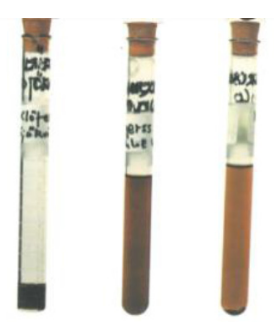

Figure 6: Organic matter (yellow/brown) dissolved from Quaternary marine illitic clays.

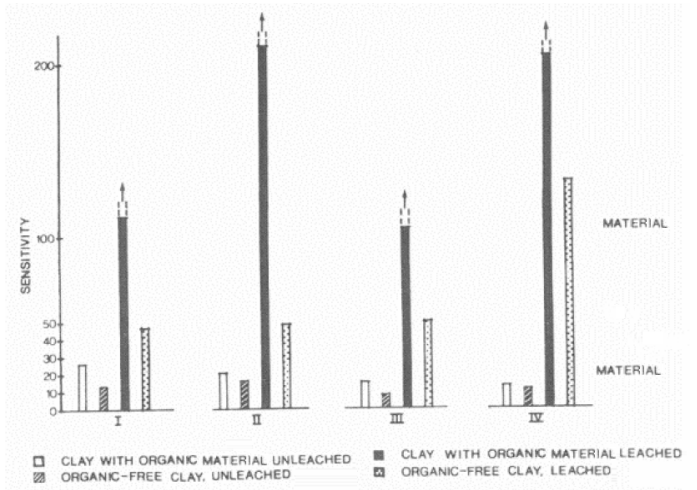

Figure 7: Sensitivity $\left(S_{\mathrm{t}}\right)$ of organic (III, IV) and organic-poor (I, II) illitic clay from 4 to $11 \mathrm{~m}$ depth, leached by distilled water [4]. Note that all samples of virgin (unleached) clay were normally sensitive $\left(S_{\mathrm{t}} 12-25\right)$ and all leached samples 'quick' $\left(S_{\mathrm{t}}>100\right)$. The leached organic-poor clays were highly sensitive $\left(S_{t}\right.$ about 50) to 'quick' $\left(S_{t}>100\right)$ [4]. 
substances serve to cause cementation of unleached marine clays but are dissolved and lost by percolation with freshwater or low-salt water. The latter explanation means that the shear resistance by remoulding is reduced and that the ratio of the shear strength of mechanically undisturbed and remoulded clay, i.e. the sensitivity, increases.

\subsection{Creep behaviour}

A way of testing whether and how organic substances in clay affect the shear resistance is offered by creep (rheological) testing, in which a clay sample is exposed to a deviatoric stress in a direct shear apparatus or triaxial cell with high-precision recording of the time-related shear strain. The theoretical background of shearing-induced creep strain development under constant volume conditions is described here to begin.

\subsubsection{Basic model}

If the passage of slip through the element of dimensions ' $L$ ' in Fig. 8 displaces the part above the slip plane by an amount ' $b$ ' over the plane the resulting shearing is $b / L$ [8]. If a slip unit - a group of atoms or molecules - does not traverse the whole element but only a certain distance on making an activated 'jump' under the local stress field and thereby produces displacement over an area $A^{*}$, it contributes to the to the bulk creep strain and amount $A * / L^{2}$ times smaller than $\mathrm{b} / \mathrm{L}$, i.e.

$$
\gamma=(b / L) \times\left(A^{*} / L^{2}\right)
$$

Following Pusch and Feltham $[1,8]$, one can take the frequency of jumps given by Arrhenius' rate equation:

$$
t_{\mathrm{A}}^{-1}=\mathrm{ne}^{-u / k T}
$$

where is 'dwell-time', $u$ is the energy barrier height and $v$ the lattice frequency of the order of E11 per second.

At any given temperature, the $u$-spectrum $u_{1}<u<u_{2}$ (Fig. 9) has a different shape since low barriers are overcome and lost and higher ones activated. The slip units may change configuration or find themselves in modified internal stress fields, meaning that the activation energy for subsequent transitions may be increased or decreased.

If slip has been activated at a certain point, meaning that a barrier has been overcome, a contribution to the overall shear strain has been made by the extension of the local slip patch. Summarizing the contributions due to jumps over all barriers we find, according to Pusch and

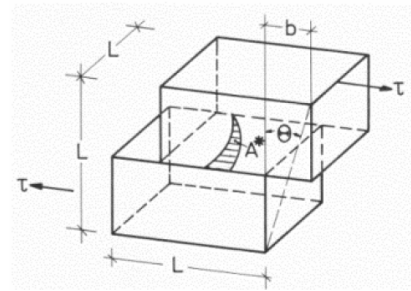

Figure 8: Clay element undergoing internal displacement caused by a slip unit jump generated by the local shear stress $\tau$ [8]. 


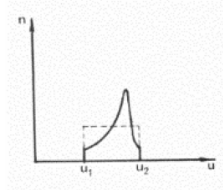

Figure 9: Energy barrier spectrum during creep. The peak shifts to the right, i.e. to higher energies, with time and strain.

Feltham [1], with minor approximations, the strain rate $\delta \gamma / \delta t$ to be proportional to $\left(t+t_{\mathrm{o}}\right)^{-1} \cdot t_{\mathrm{o}}$ is an integration constant that can be understood by considering that, in the course of applying the deviator stress, at the onset of creep, the stress rises from zero to its nominal, final values. $t_{\mathrm{o}}$ can also be regarded as retardation time.

3.6.2 Examples of clays of different origin and with different organic contents

The basic creep equation in (eqn (2)) explicitly contains a stress factor of exponential type and a temperature factor implying a relatively small effect for the temperature range $5-15^{\circ} \mathrm{C}$ that is relevant for Quaternary, shallow soils.

$$
\delta \gamma / \delta t=\beta \theta /\left(1+t / t_{\mathrm{o}}\right)
$$

where $\beta$ is a stress function and $\theta$ a temperature function. Focusing on the strain rate as the most important rheological parameter, we will show here that it is systematically lower for organic-poor clays $(<1 \%)$ than for organic-rich clays $(>3 \%)$, respectively. Comparison requires that the relative deviatoric stress level is similar for the clays represented here by a level corresponding - except for one of them (D) - to one-third of the conventionally determined undrained shear strength. It is obvious from the graph in Fig. 10 that the moderately loaded saltwater clays A, B, C all show nearly the same strain rates of log-time type, hence obeying eqn (2), while the more organic freshwater clays deform quicker and undergo larger creep strain. These clays are expected to behave like the saltwater clay D at prolonged loading, i.e. with increasing strain rate after reaching a minimum rate. $\mathrm{D}$ was loaded to threefourth of the conventionally determined undrained shear strength, which would ultimately lead to a critical state $[12,13]$.

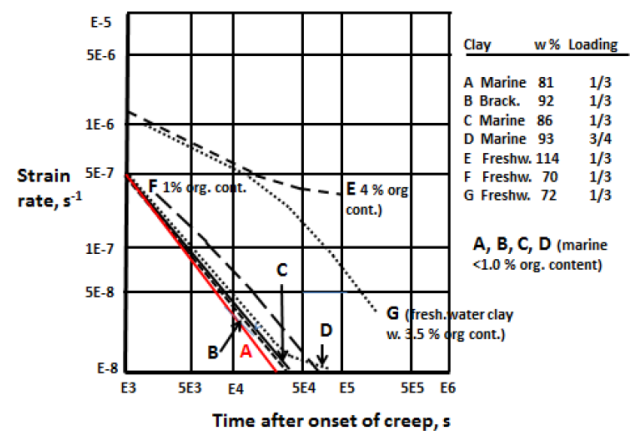

Figure 10: Shear strain rate (creep rate) as a function of organic content and stress level. 
3.7 Creep mechanisms on the microstructural scale

\subsubsection{General}

We have seen that the investigated natural freshwater clays exposed to a constant shear stress corresponding to one-third of the undrained shear strength, hence representing a safety factor of 3, followed the log-time rule in eqn (2), which implies that the creep rate drops successively and ultimately stagnates. This represents 'primary creep'. The saltwater clay D, exposed to three-fourth of the shear strength, implying a safety factor of 1.33 , logically showed a somewhat higher creep rate than the other saltwater clays and a tendency to undergo accelerated strain after about 3E4 s. This suggests that a state of critical strain was approached, implying initiation of 'secondary creep' with constant strain rate, which unconditionally leads to failure.

\subsubsection{Evolution of creep}

The evolution of creep in clay according to the cited model proposed by Pusch and Feltham [1] can be illustrated by means of the DENEB computer code developed by Feltham and Miles [13] for numerical integration of the equations governing the thermal activation of discrete, independent dislocation segments across energy barriers [13]. One of their models has been applied to illustrate creep in clay as summarized here. The basis for the formulation of the code was that a slip unit has a kinetic energy, $\Delta u$, that is sufficient to overcome an energy barrier encountered, is $\mathrm{e}^{-\Delta u / k T}$. If the displacement (jump) frequency of the slip units is $v$, the number of encounters in time $\Delta t$ will be $v \Delta \mathrm{t}$. The probability $(p)$ that it is still held up by the barrier after a time $\Delta t$ is therefore:

$$
p=\left(1-\mathrm{e}^{-\Delta u / k T}\right)^{v \Delta t}
$$

The model assumes $N$ energy barrier heights uniformly distributed between $u_{1}$ and $u_{2}$ in the energy barrier spectrum (Fig. 9) that we now assume to be, initially, of box-type (i.e. spaced $\left(u_{2}-u_{1}\right) /(N-1)$ apart. Further assumptions are (1) that the total number of slip units are, at the onset of creep, uniformly distributed among the barriers, which is in agreement with the concept of a box-shaped spectrum and (2) that slip units that have overcome their current barrier are temporarily or permanently held up at the next higher or lower barrier.

The function of the model is illustrated by a case with rather wide energy spectrum, i.e. $0.1 \mathrm{eV}<u<0.9 \mathrm{eV}$, i.e. the range of hydrogen bonds. The number of barriers is taken as 1,000 , which is not critical since creep strain is a linear function of the number of slip units. We assume a box-shaped spectrum of the barriers equally divided in 10 intervals at the onset of creep. Figure 11 shows the successive redistribution of slip units held up at the boundaries $u_{1}, u_{2}$ etc., representing the boundaries between the energy intervals. One sees that the number of slip units held up at higher barriers increased successively and that intervals higher than $0.6-0.7 \mathrm{eV}$ did not participate.

The theoretical model presupposes that all jumps give the same strain contribution and that the creep rate is obtained from the calculated relationship between $n(u, t)$ and $t$ as given by spectra like the ones in Fig. 10. The relevant relationship for shear strain is:

$$
\delta \gamma / \delta t=K \Sigma n\left(u_{\mathrm{i}}, \tau\right) \mathrm{e}^{-u i l k T} \quad(K \text { is a constant })
$$

$$
\text { which has the form } \delta \gamma / \delta t=K\left(1 / t+t_{\mathrm{o}}\right)
$$




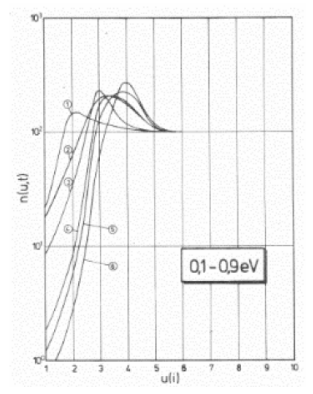

Figure 11: Number of slip units held up at different times in seconds after onset of creep: (1) $\mathrm{E} 3,(2) 5 \mathrm{E} 3,(3) \mathrm{E} 4$, (4) 5E4, (5) E5, (6) $2 \mathrm{E} 5[8,10]$.

For the energy barrier interval $0.1-0.6 \mathrm{eV}$ in Fig. 10, one gets the relationship in Fig. 12, which implies, for the straight part, log-time behaviour, and $t_{\mathrm{o}}=0$ for $t>\mathrm{E} 4 \mathrm{~s}$.

\subsubsection{Role of the number of potential slip units}

The theoretical creep model implies that low-energy barriers are overcome in the course of creep strain and that the arsenal of such barriers is high. Creep strain generates motion of slip units to be hung up on higher barriers. In practice, this means that the energy barrier spectrum undergoes 'blue-shifting' and that a majority of the interparticle bonds ultimately become under high stress. Only a small additional increase in stress level is required to cause failure

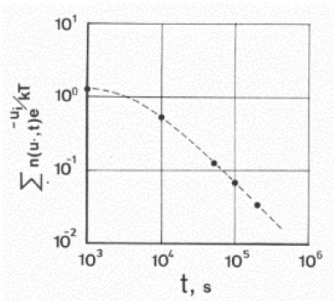

Figure 12. Relationship between $\Sigma n\left(u_{\mathrm{i}}, \tau\right) \mathrm{e}^{-\mathrm{i} / k T}$ and time $t$ in seconds.
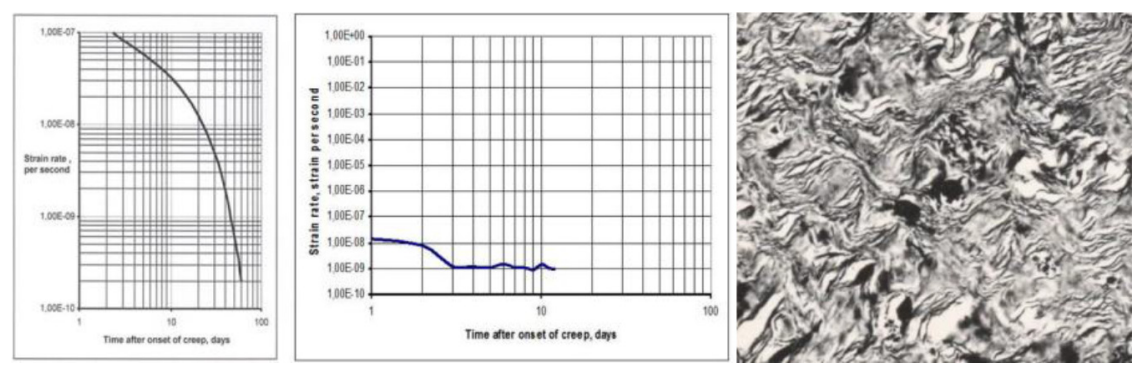

Figure 13. Creep of smectite-rich clay (MX-80) with a density at saturation with distilled water of $1,500 \mathrm{~kg} / \mathrm{m}^{3}$. Left: steeply declining curve representing primary creep for the shear stress $6 \mathrm{kPa}$. Centre: nearly constant strain rate representing secondary creep after increasing the shear stress to $23 \mathrm{kPa}$, Right: TEM of smectite, width of view $3 \mu \mathrm{m}[10]$. 
of the clay that has turned brittle. If the amount of low-energy barriers is unlimited, the clay may not fail but undergo very large strain and be flui like for moderate bulk shear stresses, in fact lower than about two-thirds of the conventionally determined undrained shear strength as found in numerous tests. This may be fulfilled by humus-rich clays and smectite clays with very large specific particle surface areas, $800 \mathrm{~m}^{2} / \mathrm{g}$ for smectites, compared with $50 \mathrm{~m}^{2} / \mathrm{g}$ for illitic clays [14]. Smectites behave in principle as illitic clays with respect to creep but sustain much larger strain (cf. Fig. 13) because of their strong arsenal of hydrogen bonds that can be mobilized. These bonds serve as particle ligaments.

\section{CONCLUSIONS}

The study shows that organic matter in sedimentary illitic clay is strongly attached or integrated in clay particle aggregates and that it significantly affects the geotechnical properties of ordinary clays with an organic content exceeding about $1 \%$ by weight. The major findings were:

- The practically most important role of organic matter in clay is its impact on time-dependent shear strain (creep) under undrained and drained conditions. For illitic clay with higher organic content than about $1 \%$ by weight, creep strain is larger than for organic-poor illitic clay and higher content than $3 \%$ makes the difference substantial and practically very important.

- The increase in creep rate caused by increased organic content can be explained by considering the spectrum of energy barriers that have to be overcome for causing slip on the microstructural scale. The spectrum is changed to contain successively more high-energy barriers, hence undergoing 'blue-shift' and causing retardation of the creep rate. For higher bulk safety factors than about three the creep rate is attenuating and of 'primary' type, while lower safety factors imply accumulation of microstructural defects that can lead to 'secondary creep' with large strain and, ultimately, to 'tertial' creep and failure [15].

- Quickness, i.e. very high sensitivity to mechanical disturbance, can be explained by loss of reinforcing organic matter and coagulating cations in particle aggregates by leaching of low-electrolyte water. The reason is an increase in negative particle charge in combination with loss of aggregate-reinforcing organic matter.

\section{REFERENCES}

[1] Pusch, R. \& Feltham, P., A stochastic model of the creep of soils. Géotechnique, 30(4); pp. 497-506, 1980. DOI: 10.1680/geot.1980.30.4.497.

[2] Bockheim, J.G., Gennadiyev., A.N., Hartemink, A.E. \& Brevik, E.C., Soil-forming factors and soil taxonomy. Geoderma, 226, 231-237, 2014. DOI: 10.1016/j.geoderma. 2014.02.016.

[3] Dagan, T. \& Martin, W., Getting a better picture of microbial evolution en route to a network of genomes. Philosophical Transactions of the Royal Society of London. Series B, Biological Sciences, 364, pp. 2187-2196, 2009. DOI: 10.1098/rstb.2009.0040.

[4] Pusch, R., Influence of Organic Matter on the Geotechnical Properties of Clays, National Swedish Council for Building Research: Stockholm, Document D11, 1973.

[5] Semprucci, F., Moreno, M., Brocca, S., Rocchi, M., Albertelli, G. \& Balsamo, M., The nematode assemblage as a tool for the assessment of marine ecological quality status: A case-study in the Central Adriatic Sea. Mediterranean Marine Science, 14(1). http:// www.medit-mar-sc.net (accessed 2013). DOI: 10.12681/mms.366, 2013. 
[6] Ovcharenko, F.D., Nichiporenko, S.P.K. \& Tretinnik, V.Y., Investigation of the PhysicoChemical Mechanics of Clay-Mineral Dispersions. Academy of Sciences, Ukrainian SSR. Transl. by Israel Programme for Scientific Translations: Jerusalem, 1967.

[7] Smart, P. \& Tovey, N.K., Electron Microscopy of Soils and Sediments: Examples. Clarendon Press \& Oxford Science Publications: Oxford, 1981.

[8] Pusch, R., Creep of soils. Schriftenreihe des Instituts fuer Grundbau, Wasserwesen und Verkehrswesen, Heft 5, Ruhr-Universität Bochum: Bochum, 1979.

[9] Nelson, P.N., Oades, J.M., Churchman, J. \& Clarke, P., Dispersed clay and organic matter in soil: Their nature and associations. Australian Journal of Soil Research, 37(2), 1999. DOI: $10.1071 / \mathrm{S} 98076$

[10] Pusch, R. Bentonite Clay. Taylor and Francis: Oxford, New York, 2015.

[11] Rasheed, S.M.K. The effect of clay content and land use on dispersion ratio at different locations in Sulaimani Governorate - Kurdistan Region - Iraq. Open Journal of Soil Science, 6, 1-8, 2016. DOI: 10.4236/ojss.2016.61001.

[12] Vaid, Y.P. \& Campanella, R.G., Time-dependent behaviour of undisturbed clay. Journal of the Geotechnical Engineering Division, ASCE 103/7(693-709), 1977.

[13] Feltham, P. \& Miles, G., DENEB - A Computer Code for Numerical Integration of the Equations Governing the Thermal Activation of Discrete, Independent, Dislocation Segments Across Energy Barriers, Internal Report of Department of Physics: Oxford \& London, 1976.

[14] Carter, D.L., Mortland, M.M. \& Kemper, W.D., Specific surface. American Society of Agronomy - Soil Science Society of America, methods of soil analysis, part I. Physical and mineralogical methods. Agronomy Monograph No. 9, 2nd ed., 1986.

[15] Alexandre, G., Ian Martins, I. \& Santa Maria, P. Creep Prediction of an Undisturbed Sensitive Clay. HAL Id: hal-00880388, 2013. 